\title{
FGFR3 Mutation Analysis
}

National Cancer Institute

\section{Source}

National Cancer Institute. FGFR3 Mutation Analysis. NCI Thesaurus. Code C157181.

A procedure used to detect and identify mutations in the FGFR3 gene. 